\title{
Investigation on Stray Magnetic Field of High-Speed Maglev
}

\author{
Yan Sun *, Chang-Young Lee **, Jeong-Min Jo **, Jin-Ho Lee **, and Young-Jae Han **
}

\begin{abstract}
Magnetic fields (MF) generated both on board the vehicle and along the guideway provide levitation and propulsion forces. High speed maglev trains adopt electromagnet or superconducting magnet to realize levitation and propulsion functions. However, stray fields existing in passenger compartment and regions surrounding the vehicle and guideway have effect on passengers and environment. To investigate stray magnetic field effect, model of Transrapid and MLX are studied.
\end{abstract}

Keywords: High-speed maglev, Stray magnetic field, Transrapid, MLX

\section{Introduction}

Maglev is a system of transportation that uses magnet to suspend, guide and propel vehicles rather than using mechanical methods, such as wheels, axles and bearings. It is considered to be a very promising solution for the future transportation and many researches, such as principles analysis and modeling, have been done since 1934 when Hermann Kemper patented it. State-of-the-art of maglev train technologies including levitation, propulsion, guidance and transfer of energy to vehicle are investigated [1]. Leading by Germany, Japan and China, high speed maglev researches has been developed steadily till now. The first commercial line operates in China and the newest maglev L0 train in Japan hits the new record of $311 \mathrm{mph}$. However, the electromagnetic interference caused by stray field is not fully studied and the effect of leakage flux to human body and environment needs more study. To analyze magnetic field distribution of electromagnet and superconducting magnet, 2D model of Transrapid and MLX are simulated by Maxwell.

The rest of this paper is organized as follows. In section 2, we will describe operation principle of two typical highspeed maglev system, transrapid and MLX01 for Yamanashi maglev test line. Configuration and parameters of LSM model of transrapid and superconducting magnet of MLX is displayed in section 3, section 4 shows the modeling and simulation result and conclusions are made in the final part.

\footnotetext{
Dept. of Railway System Engineering, University of Science \& Technology, Korea (sunyan@krri.re.kr)

** New Transportation Systems Research Center, Korea Railroad Research Institute, Korea Received 18 October 2013; Accepted 28 November 2013
}

\section{Description of High-Speed Maglev}

\subsection{Operation Principle of Transrapid System}

From Fig.1 and Table.1, we can get a brief understanding of German high-speed maglev. For Transrapid system, attractive force is produced by electromagnets and propelling force is generated by LSM. Levitation electromagnets attached to the vehicle bogie also work as excitation electromagnets for LSMs. Guidance electromagnets provide lateral stabilization. Suspension and guidance electromagnets and vehicle electric system are supplied by contactless linear generators. Long stator of LSM is installed in two parallel rows at both sides of the guideway. Stator pack has a laminated core with slots as in a typical a.c. linear motor. The three phase winding is made of a cable with synthetic elastomer insulation and the windings are fixed in the stator pack slots.
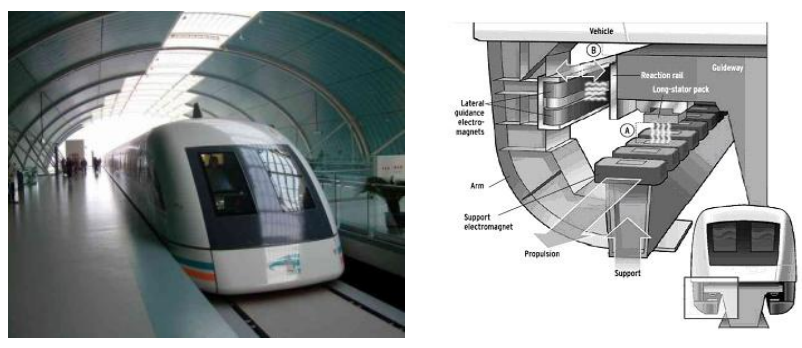

(a) Shanghai maglev (b) Electromagnets configuration Fig. 1. The German high-speed maglev (Transrapid)

The attractive and lateral forces are controlled by currents of support and guidance electromagnets, respectively. The thrust can be varied only by the magnitude and phase angle of the LSM excitation current. By reversing the phase sequence, LSM became 
synchronous generators which then provide electrodynamic braking forces without any contact. The braking energy is fed back to the network.

To reduce energy consumption, the long stator LSM of the guideway is divided into sections. Only that section in which the vehicle is running is switched on. [2]

Table 1. Specifications for Shanghai maglev

\begin{tabular}{|l|l|}
\hline Specification & Values \\
\hline Number of cars & 2-middle car, 2-end car \\
\hline Max. mass of full loaded cars & $188 \mathrm{t}$ \\
\hline Passenger capacity & 245 persons \\
\hline Max. speed & $500 \mathrm{~km} / \mathrm{h}$ \\
\hline Max. acceleration & $1.5 \mathrm{~m} / \mathrm{s} 2$ \\
\hline Levitation height & $8 \mathrm{~mm}$ \\
\hline Pole pitch of electromagnets & $258 \mathrm{~mm}$ \\
\hline
\end{tabular}

\subsection{Yamanashi Maglev MLX}

From Fig.2 and Table.2, we can get information of technical specification and ground coil configuration about Yamanashi maglev test line. The experimental maglev train MLX01 for Yamanashi Test Line is suspended on the principle of EDS (Electrodynamic Suspension) where the repulsive forces are produced between stationary shortcircuited coils and moving superconducting magnet. The track is U-shaped and embraces the bottom of the vehicle. At each side of the track, no-powered short-circuited coils serving both as levitation and lateral guideway coils are mounted in vertical position. The vehicle is equipped with superconducting magnets. In addition, a three-phase propulsion vertical winding fed with three-phase current is installed at each side of the track, which, together with onboard superconducting magnets, forms an air-cored LSM The three-phase stationary winding corresponding to armature winding of conventional motor produces a travelling magnetic field. The onboard superconducting magnet corresponds to excitation system of conventional synchronous motor. [3]

Table 2. Technical specifications for MLX01 maglev train

\begin{tabular}{|l|l|}
\hline Specification & Values \\
\hline Number of cars & 3 -middle car 2-end car \\
\hline $\begin{array}{l}\text { Max. mass of full loaded } \\
\text { cars }\end{array}$ & $120 \mathrm{t}$ \\
\hline Passenger capacity & $270 \mathrm{persons}$ \\
\hline Max. speed & $550 \mathrm{~km} / \mathrm{h}$ \\
\hline Max. acceleration & $2.5 \mathrm{~m} / \mathrm{s}^{2}$ \\
\hline Levitation height & $100 \mathrm{~mm}$ at $550 \mathrm{~km} / \mathrm{h}$ \\
\hline $\begin{array}{l}\text { Pole pitch of } \\
\text { electromagnets }\end{array}$ & $1.35 \mathrm{~m}$ \\
\hline
\end{tabular}

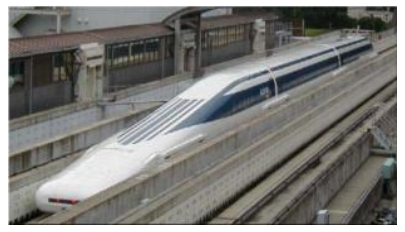

(a) Yamanashi Maglev MLX01

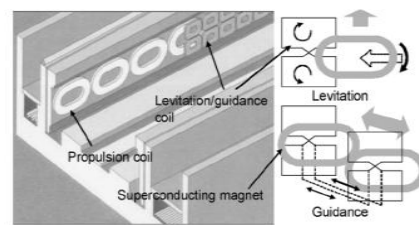

(b) Ground coil

\section{Configuration and Parameters}

\subsection{LSM of Transrapid}

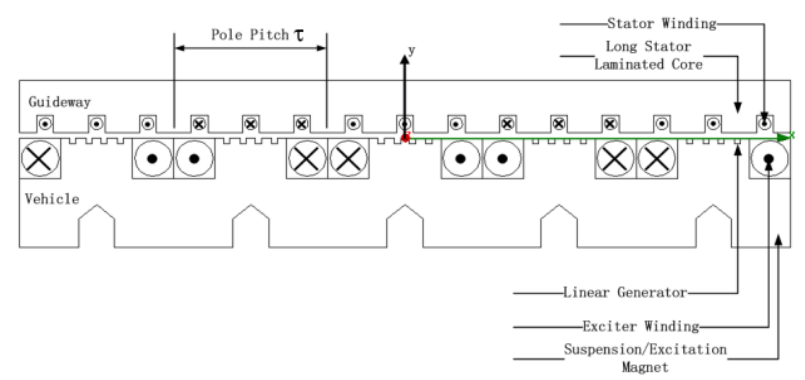

Fig. 3. LSM design of Transrapid

Long stator LSM design of transrapid is shown in Fig.3 and Table. 3 gives the corresponding parameters [4][5]. Pole pitch $\tau$ of stator and motor are equal and the length is $258 \mathrm{~mm}$. Height of stator and motor are $91.5 \mathrm{~mm}$ and $190 \mathrm{~mm}$ respectively, and width of this model is set as $185 \mathrm{~mm}$. Stator windings are supplied with 3-phase AC current and suspension magnet onboard vehicle is excited by DC current of 1000A.

Linear generators can derive power from electromagnetic field when the vehicle is in operation, but it is not taken into consideration in order to simplify the model.

Table 3. Parameter of LSM configuration

\begin{tabular}{|c|c|c|}
\hline \multicolumn{2}{|c|}{ Specification } & Value \\
\hline \multirow{4}{*}{ Stator pack } & Pole pitch & $258 \mathrm{~mm}$ \\
\hline & Height & $91.5 \mathrm{~mm}$ \\
\hline & Width & $185 \mathrm{~mm}$ \\
\hline & Current & 3-phase AC current \\
\hline \multirow{2}{*}{$\begin{array}{c}\text { Movement } \\
\text { pack }\end{array}$} & Height & $190 \mathrm{~mm}$ \\
\hline & Current & 1000A (DC current) \\
\hline
\end{tabular}

\subsection{Superconducting Magnet of MLX}

Fig.4 shows prototype of Superconducting Magnet. The SCM (SuperConducting Magnet) is the core element of superconducting Maglev. Two SCMs are symmetrically mounted on each bogie. The propulsion coils located on the 
sidewalls on both sides of the guideway are energized by a three-phase alternating current from a substation, creating a shifting magnetic field on the guideway. The on-board superconducting magnets are attracted and pushed by the shifting field, propelling the Maglev vehicle. Each SCM has $4 \mathrm{SC}$ coils $(1.07 \mathrm{~m} \times 0.5 \mathrm{~m})$ and the coil center is above the guideway of $0.57 \mathrm{~m}$. Pole pitch for SCM is $1.35 \mathrm{~m}$.
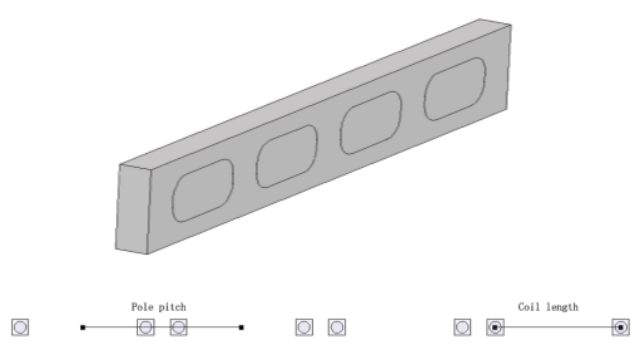

Fig. 4. Superconducting magnet of MLX

Table 4. Specifications of SCM

\begin{tabular}{|l|l|l|}
\hline \multicolumn{2}{|c|}{ Specification } & \multicolumn{1}{c|}{ Value } \\
\hline $\begin{array}{l}\text { Carbody } \\
\text { dimension }\end{array}$ & Height & $3.32 \mathrm{~m}$ \\
\cline { 2 - 3 } & Width & $2.90 \mathrm{~m}$ \\
\hline \multirow{4}{*}{$\begin{array}{l}\text { Supercond } \\
\text { uctive } \\
\text { magnet } \\
\text { (SCM) }\end{array}$} & $\begin{array}{l}\text { Layout } \\
\text { (symmetrical on both sides) }\end{array}$ & 4pole, 2row \\
\cline { 2 - 3 } & Pole pitch & $1.35 \mathrm{~m}$ \\
\cline { 2 - 3 } & SC coil dimension & $1.07 \mathrm{~m} \times 0.5 \mathrm{~m}$ \\
\cline { 2 - 3 } & $\begin{array}{l}\text { Magnetomotive force } \\
\text { Fitted height (height above }\end{array}$ & $700 \mathrm{kA}$ \\
\hline & SC coil center in wheel run) & $0.57 \mathrm{~m}$ \\
\hline
\end{tabular}

\section{Modeling and Simulation}

Magnetostatic model is applied to analyze magnetic field distribution of electromagnet for transrapid and superconducting magnet for MLX.

\subsection{Magnetic Flux Line Distribution}

After assigning excitation to magnet, we can observe sim ulation result of flux line distribution as shown in Fig.5. For transrapid model, most of the flux lines form close curve a long the stator core and suspension magnet, but some of the flux lines leak into the surrounding area. Although the stra y flux lines are not visible in Fig.5(a), their existence can be proved by Fig.6. For MLX model, visible flux lines flow $\mathrm{t}$ hough the space, and magnetic field density will be calculat ed for the further analysis.

\subsection{Magnetic Field Density Along y-axis}

Relationship between magnetic field density and distance along y-axis for transrapid model is plotted in Fig.6(a), field density value decreases from base point to position1, and then undergoes rapid increase and decrease in the iron material, and the value continue to decrease till 1.5 meter. Reason for density variation along y-axis is that air is assigned for the space from base point to position 1 and the space from position 3 to 1.5 meter, and iron is assigned for guideway from position1 to position3 as shown in Fig.5(a). Relationship between magnetic field density and distance along y-axis for MLX model is plotted in Fig.6(b), field density first increase and then decrease in accordance with flux line distribution in Fig.5(b). After a turning point, field density decreases as distance increases for both models, but electromagnet has less stray field contamination. Because density values at $1.5 \mathrm{~m}$ of MLX model is larger than that of transrapid model almost three orders of magnitude.

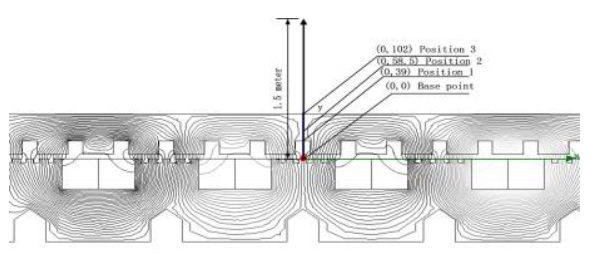

(a) Electromagnet model

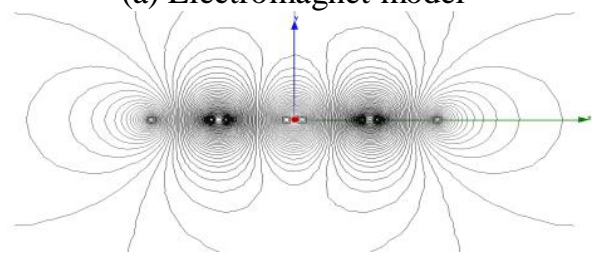

(b) Superconductive magnet model

Fig. 5. Magnetic flux line distribution

\subsection{Magnetic Field Density Along y-axis}

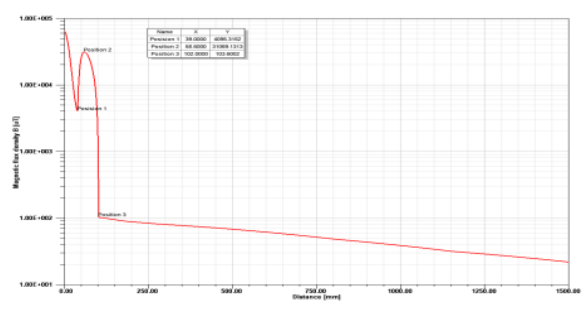

(a) Electromagnet model

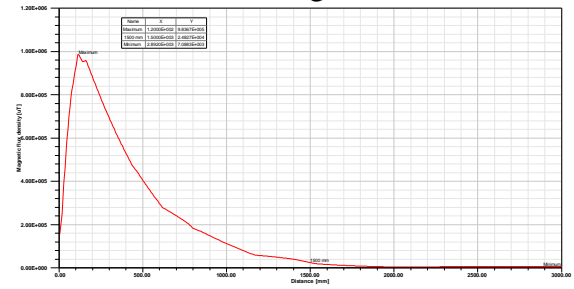

(b) Superconductive magnet model

Fig. 6. Magnetic field density along y-axis 
Relationship between magnetic field density and distance along y-axis for transrapid model is plotted in Fig.6(a), field density value decreases from base point to position 1 , and then undergoes rapid increase and decrease in the iron material, and the value continue to decrease till 1.5 meter. Reason for density variation along y-axis is that air is assigned for the space from base point to position 1 and the space from position 3 to 1.5 meter, and iron is assigned for guideway from position 1 to position 3 as shown in Fig.5(a). Relationship between magnetic field density and distance along y-axis for MLX model is plotted in Fig.6(b), field density first increase and then decrease in accordance with flux line distribution in Fig.5(b). After a turning point, field density decreases as distance increases for both models, but electromagnet has less stray field contamination. Because density values at $1.5 \mathrm{~m}$ of MLX model is larger than that of transrapid model almost three orders of magnitude.

\subsection{Passenger Compartment Evaluation}

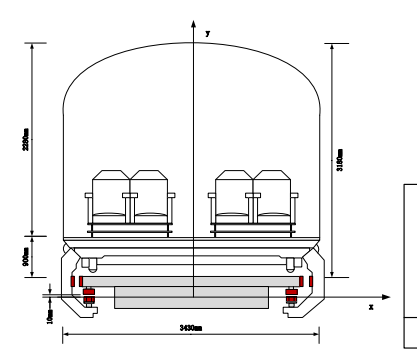

(a) Transprapid model

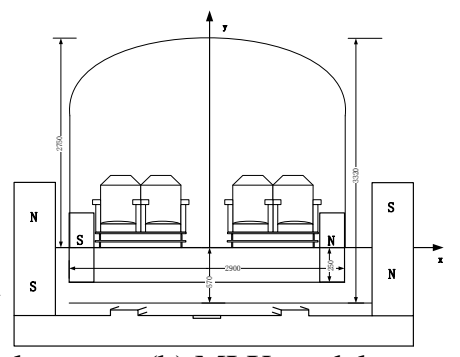

(b) MLX model
Fig. 7. Cross section view of Transrapid and MLX

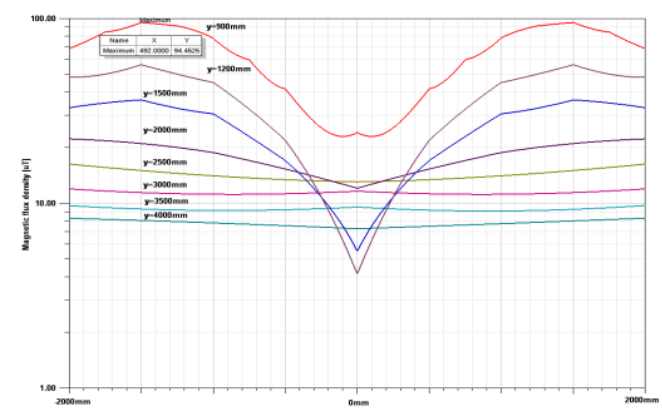

(a) Electromagnet model

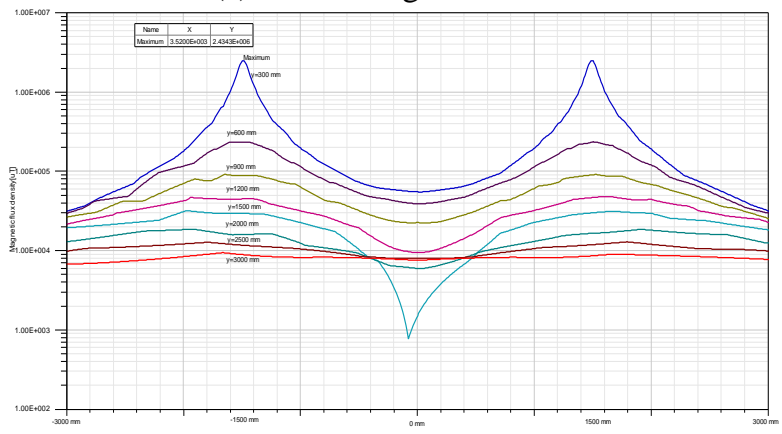

(b) Superconductive magnet model

Fig. 8. Magnetic field density of passenger compartment
Fig.7 shows cross section view of both transrapid and MLX. Field density variation at cross section can be observed by simulation result, and according to the result we can estimate stray field density in user compartment. According to car body design, passenger compartment floor is around $900 \mathrm{~mm}$ for transrapid model and $300 \mathrm{~mm}$ for MLX model.

From Fig. 8(a), it is easy to get that magnetic flux density of transrapid model decreases with increment of $y$ value except the aisle section and maximum value is at the passenger seat area which is about 0.945 Gauss (94.5uT) when y is $900 \mathrm{~mm}$. And from Fig.8(b), we can get the same conclusion except that the field density value has more than four orders of magnitude difference (maximum value is $2.4 \times 104$ Gauss when y is $300 \mathrm{~mm}$ ).

\section{Conclusion}

To make comparison, we find the magnetic field intensity of earth which ranges from about 0.25-0.65Gauss [7]. And typical magnetic field strength of household appliances at various distances is listed in Table.5. With most household appliances the magnetic field strength at a distance of 30 $\mathrm{cm}$ is well below the guideline limit for the general public of 1 Gauss[8].

Table 5. Magentic field intensity of electric appliance

\begin{tabular}{|l|l|l|l|}
\hline $\begin{array}{l}\text { Electric } \\
\text { appliance }\end{array}$ & $3 \mathrm{~cm}$ distance & $30 \mathrm{~cm}$ distance & $1 \mathrm{~m}$ distance \\
\hline Hair dryer & $0.06-20$ & $10^{-4}-0.07$ & $10^{-4}-3 \times 10^{-4}$ \\
\hline $\begin{array}{l}\text { Electric } \\
\text { shaver }\end{array}$ & $0.15-15$ & $8 \times 10^{-4}-0.09$ & $10^{-4}-3 \times 10^{-4}$ \\
\hline $\begin{array}{l}\text { Vacuum } \\
\text { cleaner }\end{array}$ & $2-8$ & $0.02-0.2$ & $13 \times 10^{-4}-0.02$ \\
\hline $\begin{array}{l}\text { Microwave } \\
\text { oven }\end{array}$ & $0.73-2$ & $0.04-0.08$ & $2.5 \times 10^{-3}-\times 10^{-3}$ \\
\hline Computer & $5 \times 10^{-3}-0.3$ & $<10^{-4}$ & - \\
\hline Color TV & $0.025-0.5$ & $4 \times 10^{-4}-0.02$ & $10^{-4}-15 \times 10^{-4}$ \\
\hline
\end{tabular}

※Federal Office for Radiation Safety, Germany 1999 (unit:Gauss)

According to this standard, magnetic field density value is analyzed from simulation result in section 4. Passenger compartment of transrapid floats above the guideway and the model only shows the LSM winding attached to guideway, so at least we should observe the flux density from position3 in Fig.5(a). From simulation result in Fig.6(a), the magnetic field density is about 1 Gauss and the value declines as the observation point moves farther from position3. From Fig.7(a), we can get that distance from origin point to passenger compartment floor is longer than $900 \mathrm{~mm}$ and we already get that maximum value of 
magnetic field density is about 0.945 Gauss when y is $900 \mathrm{~mm}$. So we can infer flux density value at compartment floor is less than 0.945 Gauss. Similar analysis has done to estimate field density in MLX train compartment. However, the maximum magnetic field density value is $2.4 \times 104$ Gauss when y is $300 \mathrm{~mm}$, which is much larger than the standard.

So far, the conclusion is that, for transrapid model, stray field existing in passenger compartment and surrounding area is less than guideline limit of 1 Gauss, so it is not a threaten to human body. However, we need a magnetic shield to protect passenger from stray field contamination for MLX model.

\section{Acknowledgements}

This work was supported by Core Technology Development Project of Super Speed Maglev Train funded by Ministry of Land, Infrastructure and Transport. (11PRTD-B061485)

\section{References}

[1] Hyung-woo Lee, Ki-Chan Kim, and Ju Lee, "Review of Maglev Train Technologies," IEEE Transactions on Magnetics, Vol.42, No.7

[2] Jacek F. Gieras and Zbigniew J. Piech, Linear Synchronous Motors, Transportation and Automation Systems, PP. 180183

[3] Jacek F. Gieras and Zbigniew J. Piech, Linear Synchronous Motors, Transportation and Automation Systems, PP. 195

[4] Dr.-Ing. Klaus Heinrich, Dipl._Ing. Rolf Kretzschmar, Transrapid Maglev System, pp.50-51

[5] James H. Lever, "Technical Assessment of Maglev System Concepts, Special Report 98-12," pp. 88-100

[6] http://www.rtri.or.jp/rd/division/rd79/yamanashi/english/magl ev_frame_E.html

[7] http://en.wikipedia.org/wiki/Geomagnetic_field

[8] http://www.who.int/pehemf/about/WhatisEMF/en/index3.html

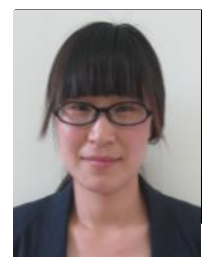

Yan Sun received Master degree in electron ics and radio engineering from Kyunghee $u$ niversity. She is now a $\mathrm{Ph}$. D. candidate of University of Science \& Technology in Rail way system engineering. Her research inter est is super-speed maglev system.

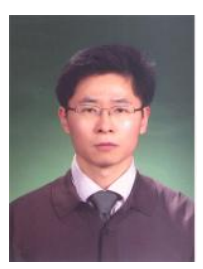

Chang-Young Lee received Ph.D. degree in electrical engineering from Yonsei University. His research interests are propulsion system and high field electromagnet for railway system.

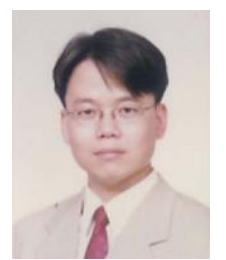

Jeong-Min Jo received Ph.D. degree in electrical engineering from Myongji University. His research interests are Electro-magnetic suspension control and linear motor control.

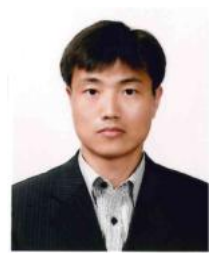

Jin-Ho Lee received Ph.D. degree in mechanical engineering from University of Florida. His research interests are mechanical control and train vehicle system.

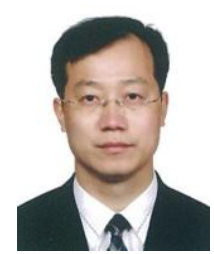

Young-Jae Han received Ph.D. degree in electrical \& control engineering from Hongik University. His research interests are propulsion and measurement system for electric railway. 